\title{
OPTIMASI JARINGAN SERAT OPTIK MENGGUNAKAN METODE ALGORITMA GENETIKA
}

\author{
(STUDI KASUS UNISMA) \\ Diki Okiandri ${ }^{1}$, Sholeh Hadi Pramono ${ }^{2}$, Erni Yudaningtyas ${ }^{3}$
}

\begin{abstract}
${ }^{1}$ Mahasiswa Program Studi Magister S2 Teknik Elektro Fakultas Teknik Universitas Brawijaya, P3tik Unisma J1.Mt. Haryono 193 Malang 65144, INDONESIA (tlp: 0812-33244848;)

${ }^{2}$ Sholeh Hadi Pramono, dosen Jurusan Teknik Elektro, Fakultas Teknik, Universitas Brawijaya, Malang, INDONESIA

${ }^{3}$ Erni Yudaningtyas, dosen Jurusan Teknik Elektro, Fakultas Teknik, Universitas Brawijaya , Malang, INDONESIA
\end{abstract}

Email: ${ }^{1}$ dikiokiandri@gmail.com, ${ }^{2}$ sholehhadipramono@ub.ac.id, ${ }^{3}$ erni@ub.ac.id

(Naskah masuk: 18 Februari 2016, diterima untuk diterbitkan: 17 Maret 2016)

\begin{abstract}
Abstrak
Abstrak--Peningkatan penggunaan komputer di kampus pendidikan mengakibatkan lalu lintas data yang padat pada jaringan komunikasi. Di Universitas Islam Malang (Unisma) terdapat lebih dari 500 komputer yang terkoneksi dengan internet menggunakan media kabel dan akses hotspot. Infrastruktur jaringan eksisting di Unisma saat ini menggunakan kabel Backbone Fiber Optic Multimode dengan routing static dan topologi yang dipakai adalah topologi Mesh. Banyaknya pengguna yang berkomunikasi di jaringan mengakibatkan lalu lintas data yang padat sehingga menyebabkan waktu tunda atau antrian yang lama. Algoritma genetika adalah sebuah algoritma pencarian yang didasarkan pada mekanisme genetika alamiah yang juga digunakan sebagai algoritma optimasi kinerja jaringan.Penelitian ini membandingkan kinerja jaringan eksisting dengan simulasi optimasi menggunakan Algoritma Genetika. Dilakukan pengukuran dan pengambilan data-data berupa waktu tempuh, juga dilakukan rekayasa perangkat lunak dengan bantuan visual studio untuk melakukan pemodelan sebagai pembanding. Hasilnya optimasi dengan algoritma genetika mampu mencari jalur tercepat serta meningkatkan kecepatan pengiriman paket data dengan menurunkan waktu tempuh sebesar $53.5 \%$ dan meningkatkan data rate sebesar $54.75 \%$ dibandingkan dengan metode antrian pada jalur existing.
\end{abstract}

Kata kunci: Algoritma Genetika, Backbone Fiber Optik, Optimasi, Waktu Tempuh

\begin{abstract}
Abstract-- Increased use of computers in education campus resulted in dense data traffic on communications networks. At the Islamic University of Malang (Unisma) there are more than 500 computers connected to the Internet using a wired media and hotspot access. Unisma existing network infrastructure in current use the Multimode Fiber Optic Backbone cable with static routing and Mesh topology. These lots number of users on the network resulting in dense data traffic that lead to long delays or long queues. Genetic algorithm is a search algorithm that is based on the natural genetic mechanism which also being used in optimizing network performance. This study compared the performance of existing network and a simulation of optimization using Genetic Algorithms. Measurement and retrieval of data consist of transfer time, also we built software engineering using visual studio program as a comparison model.The result of this study shows that optimization using genetic algorithm is able to find the fastest path and increase the speed of transmission of data packets by reducing transfer time by $53.5 \%$ and increase the data rate of $54.75 \%$ compared to the queuing method used on the existing network.
\end{abstract}

Keywords : Genetic Algorithm, Fiber Optic Backbone, Optimization, Transfer time

\section{PENDAHULUAN}

Meningkatnya penggunaan komputer yang terhubung dengan jaringan mengakibatkan lalu lintas data yang padat pada jaringan backbone komputer. Peningkatan ini memerlukan. Infrastruktur komunikasi yang handal. Karena infrastruktur memegang peranan penting untuk melayani kebutuhan lalu lintas data dari satu komputer ke komputer lain yang terhubung (Anderson, J. Q., Boyles, J. L. \& Rainie, L., 2012).

Kinerja jaringan dipengaruhi oleh dua hal yaitu infrastruktur yang bagus dan sistem operasi manajemen jaringan. Adanya lalu lintas data yang padat pada backbone serat optik dapat mengganggu kinerja backbone saat melakukan pengiriman paket pada tujuan (Duck, M. \& Read, R., 2003).

Algoritma genetika yaitu suatu algoritma yang menerapkan pemahaman mengenai evolusi alamiah pada tugas-tugas pemecahan masalah (problem solving). Algoritma genetika dipelopori pertama kali oleh Holland pada tahun 1975 kemudian oleh Goldberg tahun 1989 dan seterusnya. Algoritma genetika menggabungkan berbagai pilihan solusi secara acak dalam suatu kumpulan untuk mendapatkan solusi terbaik berikutnya yang disebut fitness. Generasi ini akan merepresentasikan perbaikan-perbaikan pada populasi awalnya secara 
berulang dan diharapkan dapat mensimulasikan proses evolusioner (Lin, X-H et al., 2002)( Kumar, R. \& Kumar, M., 2012). Algoritma genetika sendiri dikembangkan sebagai sebuah solusi optimasi topologi jaringan yang mengalami kendala kehandalan (Kumar, D. R. \& Kumar, M., 2010).

Di Universitas Islam Malang (Unisma) terdapat lebih dari 500 komputer yang terkoneksi dengan internet menggunakan media kabel dan akses hotspot. Infrastruktur jaringan di Unisma menggunakan kabel Backbone Fiber Optic Multimode dan topologi yang dipakai adalah topologi Ring. Kabel serat optik digunakan sebagai kabel utama atau kabel induk penghubung dari satu gedung ke gedung lainnya yang memiliki kemampuan dalam melewatkan data sampai dengan 1Gbps (giga bytes) (Senior, J.M., 2008) (Bisht, N. \& Singh, S., 2015). Jaringan komputer menuju klien tetap menggunakan kabel UTP (Unshielded Twisted Pair). Jaringan eksisting di Unisma saat ini menggunakan routing static.

Banyaknya pengguna yang berkomunikasi di jaringan mengakibatkan lalu lintas data yang padat sehingga menyebabkan waktu tunda atau antrian yang lama (Khandelwal, G., Prasanna, G. \& Hota, C., 2011). Seiring pengembangan teknologi jaringan dan meningkatkan aplikasi berbasis jaringan, jaringan komputer saat ini banyak digunakan dalam penelitian ilmiah, bisnis, pendidikan industri, pertahanan nasional dan lainnya. Ketika dibutuhkan pengembangan desain jaringan sering kita menghadapai masalah topologi jaringan dan komunikasi semua simpul tentang pemilihan jalur dan penentuan rute antara setiap dua simpul. Hasil penelitian Lin dkk menunjukkan penggunaan New Genetic Algorithm (NGA) mampu menghasilkan penurunan dan percepatan penggunaan lebar data serta waktu pengiriman paket, sehingga mampu menyelesaikan masalah pemilihan rute dan kapasitas aliran data. (Lin et al., 2002).

Hal ini yang menjadi latar belakang pemikiran penulis tentang perlunya optimasi pada jaringan serat optik di Unisma dengan menggunakan metode algoritma genetika melalui pengamatan terhadap waktu tempuh pengiriman paket data. Optimasi jaringan diharapkan mampu memberikan solusi terhadap masalah diatas dan meningkatkan performa kinerja jaringan komputer di Unisma.

\section{METODOLOGI}

Penelitian ini termasuk dalam bidang rekayasa perangkat lunak. Metode yang digunakan adalah dengan melakukan studi perbandingan. Langkahlangkah yang dilakukan meliputi pengumpulan data awal, desain perangkat lunak, pengujian perangkat lunak, kemudian analisis perbandingan. Penelitian optimasi jaringan backbone serat optik dilakukan di
Universitas Islam Malang Jl. MT.Haryono 193 Malang.

\subsection{Jenis Dan Cara Perolehan Data}

Desain yang digunakan dalam penelitian adalah desain eksperimental, dimana dilakukan percobaan terhadap simpul-simpul jaringan dengan melakukan simulasi pemodelan terhadap topologi jaringan yang sudah ada. Pemodelan ini bertujuan untuk mendapatkan data-data sebagai pembanding.

Data diperoleh dengan cara mengumpulkan hasil pengiriman paket-paket data dalam jumlah tertentu ke perangkat-perangkat yang terhubung dengan serat optik. Proses ini menggunakan perintah network ping dan protokol FTP (file transfer protocol) yang dioperasikan pada server dan klien untuk memperoleh informasi waktu dalam bentuk angka. Setelah itu, dilakukan pemodelan dengan bantuan software.

\section{- $\quad$ Ping (packet internet gropher)}

Ping (Packet Internet Groper) adalah sebuah perintah untuk melakukan pemeriksaan koneksi perangkat, apakah perangkat yg dituju terhubung ke jaringan atau tidak melalui protocol TCP/IP. Ping akan melakukan pengiriman paket Internet Control Message Protocol (ICMP) pada perangkat tujuan dan meminta tanggapan tujuan.

Indikasi kehandalan sebuah jalur dapat dilihat dari besarnya nilai delay atau latency yang dilaporkan oleh ping. Semakin besar nilai delay menunjukkan semakin buruk kualitas jalur tersebut. Sehingga nilai delay ini dapat digunakan sebagai indikator kualitas jaringan (Bonaventure, O., 2011)

\section{- $\quad$ FTP (file transfer protocol)}

FTP adalah sebuah protocol unggah dan unduh berkas antara klien dan server yang berjalan pada lapisan aplikasi. Sebuah Klien FTP merupakan aplikasi yang dapat mengeluarkan perintah-perintah FTP ke sebuah server FTP. Sementara server FTP adalah sebuah Windows Service atau daemon yang berjalan di atas sebuah komputer yang merespons perintah-perintah dari sebuah klien FTP. Perintahperintah FTP dapat digunakan untuk mengubah direktori, mengubah modus pengiriman antara biner dan ASCII, menggugah berkas komputer ke server FTP, serta mengunduh berkas dari server FTP (Clark, M. P., 2003)

\subsection{Variabel dan Cara Analisis Data}

Variabel yang akan diukur dalam penelitian ini meliputi variabel bebas dan terikat. Variabel bebas antara lain : topologi jaringan dan routing. Variabel terikat : waktu tempuh. Analisa data dilakukan dengan cara menghitung data transaksi yang didapat oleh server, kemudian dibandingkan dengan datadata hasil simulasi. 


\subsection{Model Jaringan Existing di Unisma}

Jaringan komputer di Unisma saat ini menggunakan media kabel serat optik sebagai kabel backbone atau kabel utama yang menghubungkan antar gedung, menggunakan topologi Ring dengan mengadopsi sistem antrian. Serat optik yang digunakan adalah jenis kabel multimode dengan jumlah inti sebanyak 8 inti yang memiliki kemampuan dalam melewatkan data sampai dengan 1Gbps (giga bytes). Detail jaringan backbone Unisma dapat dilihat pada Gambar 1. Jaringan komputer menuju klien tetap menggunakan kabel UTP. Jaringan existing di Unisma saat ini menggunakan routing statis. Hubungan antara klien dan simpul diatur oleh sebuah protokol aplikasi jaringan yang disebut VLAN (Virtual Local Area Network). VLAN adalah sebuah protokol yang dapat menghubungkan klien satu dengan klien lainnya yang terpisah secara fisik jaringan tetapi dapat mengikuti aturan jaringan induknya. VLAN tidak terbatas fisik lokasi jaringan seperti LAN (Local Area Network) (Bonaventure, O., 2011)

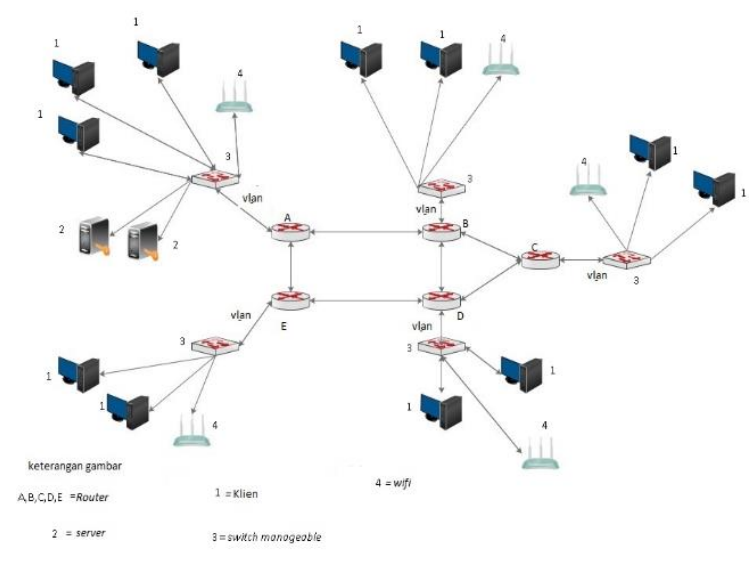

Gambar 1. Diagram Infrastruktur Jaringan di Unisma Menggunakan Kabel Backbone Fiber Optic Multimode

\subsection{Model Optimasi Menggunakan Algoritma Genetika}

Algoritma genetika yaitu algoritma pencarian berdasarkan mekanisme seleksi alami dan evolusi biologis. Pada setiap generasi, himpunan baru dari deretan individu dibuat berdasarkan kecocokan pada generasi sebelumnya dimana satu siklus iterasi (sering disebut sebagai generasi) mengalami dua proses, yakni proses seleksi dan rekombinasi. Proses seleksi adalah proses evaluasi kualitas setiap string didalam populasi untuk memperoleh peringkat calon solusi. Berdasarkan hasil evaluasi, dipilih stringstring yang akan mengalami proses rekombinasi (Abuiziah, I. \& Shakarneh, N., 2013). Pada penelitian ini langkah langkah yang dijalankan adalah:
1. Mengambil data-data simpul simpul yang terhubung dengan backbone. Berupa data-data transaksi perangkat perangkat switch dan router yang terkoneksi dengan simpul berikutnnya. Dengan jalan melakukan pengiriman paket data yang besarnya sama kemudian dilakukan pengiriman pada simpul penerima sehingga akan didapatkan waktu tempuh dari pengiriman data tersebut. Dan dilakukakan proses sebaliknya dari simpul penerima menjadi simpul pengirim.

2. Data-data kemudian diseleksi untuk dijadikan kromosom berdasarkan nilai fitness.

3. Langkah berikut dilakukan proses genetika yang dilakukan dengan bantuan software Microsoft visual studio ver. Community freeware. Hasil operasi genetika dilakukan dengan tujuan mendapatkan jalur tercepat yang optimal.

4. Langkah terakhir dilakukan perbandingan dengan teori antrian untuk melihat perbedaan optimasi yang dilakukan.

\section{HASIL DAN PEMBAHASAN}

Pengujian pada penelitian ini dilakukan terhadap data-data yang dikumpulkan dari jaringan Unisma menggunakan perintah ping dan aplikasi kirim file FTP. Implementasi data sumber dan data hasil simulasi optimasi dengan algoritma genetika dibangun menggunakan Microsoft Visual Studio version community freeware. Analisis bahasan ditekankan pada optimasi jaringan dengan menggunakan algoritma genetika.

\subsection{Hubungan Simpul dengan Klien pada Jaringan Eksisting Unisma}

Untuk kepentingan pengujian maka dibuat diagram jaringan fiber optik Unisma yang ditunjukkan pada Gambar 2, dimana gambar ini digunakan pada simulasi optimasi menggunakan metode Algoritma Genetika. Sesuai dengan topologi mesh maka terdapat 5 buah node (simpul) yaitu A, B, C, D dan E. Pengambilan data awal dilakukan menggunakan parameter waktu tempuh pengiriman paket data antar simpul berupa data ping dan FTP.

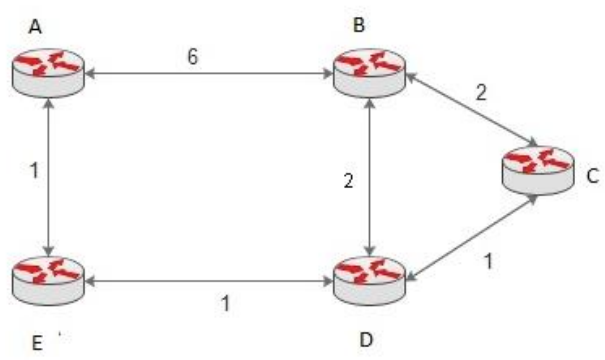

Gambar 2. Diagram Simulasi Simpul Jaringan Existing Unisma

Ketika klien dari simpul A akan menghubungi klien dari simpul $\mathrm{C}$ maka secara aturan akan melewati simpul A, B, C karena sifat routing statis. 
Hal ini akan berpengaruh pada kecepatan karena saat traffic ramai dan jalur penuh pun harus tetap melewati jalur tersebut dengan mengantri. Demikian konsep dasar mekanisme sistem operasi jaringan existing di Unisma.

\subsection{Aplikasi Simulasi Algoritma Genetika menggunakan Microsoft Visual Studio}

Visual studio adalah sebuah bahasa pemrograman yang dapat digunakan untuk pengembangan aplikasi, baik itu aplikasi bisnis, aplikasi personal, ataupun komponen aplikasinya, dalam bentuk aplikasi console, aplikasi Windows, ataupun aplikasi Web. Pada penelitian ini aplikasi simulasi dibangun untuk memecahkan masalah jalur tercepat dengan menggunakan metode algoritma genetika. Pada proses pembangunannya simulasi optimasi algoritma genetika dibangun menggunakan Microsoft visual studio ver. Community freeware. Bentuk aplikasi sebagai mana ditunjukan pada Gambar 3. Program ini berjalan sesuai dengan masukan masukan nilai bobot antar simpul yang dibuat dalam tabel excel.

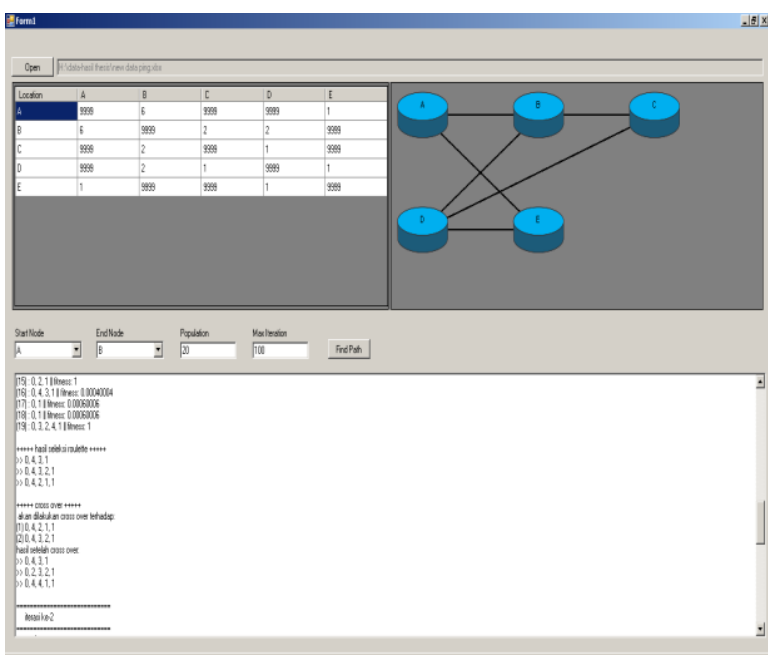

Gambar 3. Tampilan Aplikasi Simulasi Algoritma Genetika menggunakan Microsoft Visual Studio

Beberapa proses penting yang dilakukan untuk mengimplementasikan algoritma genetika dalam mencari jalur tercepat pada pembangunan simulasi program ini dijelaskan pada Gambar 4 sebagai berikut:

\section{- Inisialisasi Populasi}

Tahapan ini memiliki tujuan membangkitkan sebuah populasi sejumlah kromosom yang berasal dari simpul simpul yang ada secara acak. Proses pembangkitan populasi yang menghasilkan kromosom ditunjukan pada tabel 1.
Tabel 1. Kromosom Populasi Awal dari Simpul A ke C

\begin{tabular}{|l|c|}
\hline Kromosom & Representasi Kromosom \\
\hline Kromosom 1 & A-B-C-D-E \\
\hline Kromosom 2 & A-B-D-C-E \\
\hline Kromosom 3 & A-E-D-C-B \\
\hline Kromosom 4 & A-E-D-B-C \\
\hline
\end{tabular}

Dimana pada kromosom yang dicetak tebal adalah kromosom utama sedangkan yang tidak dicetak tebal adalah kromosom pelengkap.

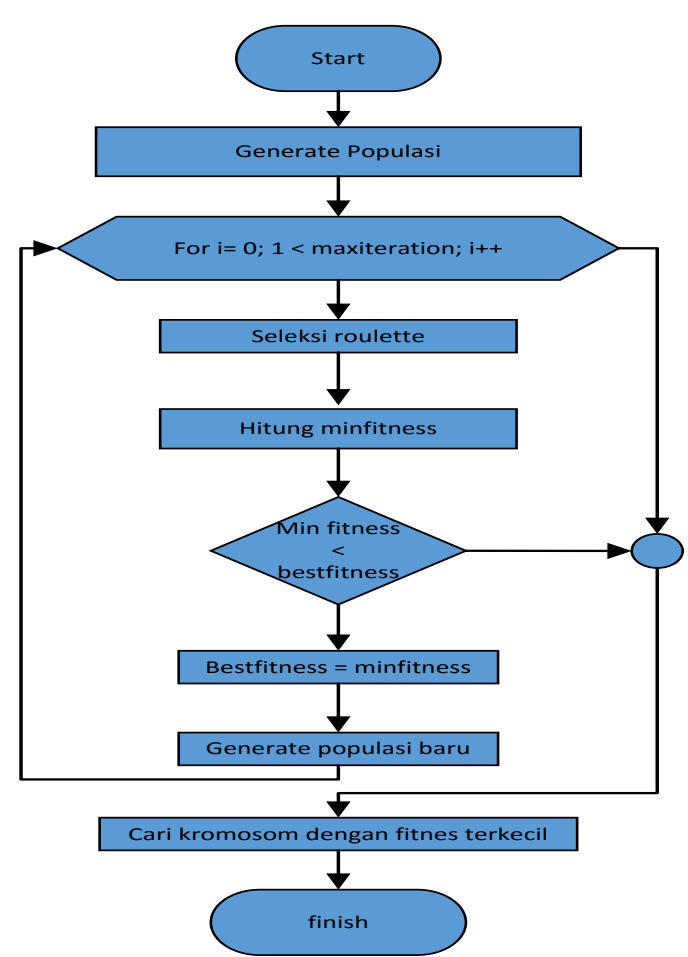

Gambar 4. Alur Pencarian Jalur Tercepat Simulasi Algoritma Genetika

\section{- Evaluasi Individu}

Fungsi fitness digunakan pada penentuan seberapa baik individu yang telah direpresentasikan oleh suatu kromosom. Pada tesis ini mencari jalur tercepat dari 5 simpul dan 6 busur diperoleh dengan menghitung fitness nya, sementara angka 9999 ditentukan sebagai batas tertinggi fitness. Penghitungan fitness adalah sebagai berikut

Fitness $=($ limit fitness - total bobot $)$

Limit fitness $=9999$

Fitness dipengaruhi oleh jalur yang terkandung dalam kromosom bersangkutan. Jika ada kromosom yang memiliki jalur tidak benar maka fitness akan bernilai nol dan itu berlaku sebaliknya apabila jalurnya benar maka nilainya sama dengan fungsi fitness yang telah ditentukan. Kromosom dari Tabel 1 kemudian didapatkan nilai fitness nya dengan perhitungan sebagai berikut: 


$$
\begin{gathered}
\mathrm{K} 1=9999-(6+2) \\
=9991 \\
\mathrm{~K} 2=9999-(6+2+1) \\
=9990 \\
\mathrm{~K} 3=9999-(1+1+1) \\
=9996 \\
\mathrm{~K} 4=9999-(1+1+2+2) \\
=9993
\end{gathered}
$$

Hasil perhitungan disusun dalam Tabel 2 dibawah ini:

Tabel 2. Fitness Kromosom Simpul A ke C

\begin{tabular}{|l|l|}
\hline Kromosom & Fitness \\
\hline Kromosom 1 & 9991 \\
\hline Kromosom 2 & 9990 \\
\hline Kromosom 3 & 9996 \\
\hline Kromosom 4 & 9993 \\
\hline
\end{tabular}

Berdasarkan perhitungan menggunakan rumus (1) maka langkah berikutnya adalah merubah nilai fitness menjadi waktu dengan persamaan:

$$
\text { Waktu }=\text { limit fitness }- \text { fitness }
$$

Dari persamaan (2) didapatkan hasil perubahan nilai fitness sebagai berikut

$$
\begin{aligned}
& \mathrm{K} 1=9999-9991=8 m s \\
& \mathrm{~K} 2=9999-9990=9 m s \\
& \mathrm{~K} 3=9999-9996=3 m s \\
& \mathrm{~K} 4=9999-9993=6 m s
\end{aligned}
$$

\section{- $\quad$ Seleksi Roulete wheel}

Setelah populasi awal terbentuk, kemudian populasi tersebut diseleksi. Seleksi yang digunakan pada program simulasi ini adalah roulete wheel selection. Metode ini digunakan untuk melakukan seleksi roulette terhadap populasi (chroms) dengan nilai fitnes (fitness) dan mengembalikan sejumlah kromosom dengan jumlah yang diinginkan (count). Besarnya probabilitas sebuah kromosom ditentukan oleh nilai fitnessnya. Semakin kecil nilai fitness sebuah kromosom, semakin besar kemungkinan kromosom tersebut untuk terseleksi

Pada metode roulette wheel, seleksi individu disamakan seperti permainan roulette wheel. Teknis permainan ini, pemain berupaya memutar roda yang telah disekat-sekat dalam beberapa bagian sekat atau partisi untuk mendapatkan hadiah. Pada simulasi program ini kromosom diibaratkan sebagai hadiah. Sekat yang ada dalam permainan roulette adalah interval nilai kumulatif probabilitas dari masingmasing kromosom. Berikut adalah urutan penyelesaian seleksi roullete wheel:
Hitung total fitness $(T f)$ :

$$
\mathrm{T} f=\sum F_{k} \quad k=1,2,3, \text { popsize }
$$

Dari persamaan diatas didapatkan hasil:

$\mathrm{T} f=9991+9990+9996+9993=39970$

Langkah selanjutnya adalah menentukan peluang individu atau probabilitas individu:

$$
\begin{aligned}
& \mathrm{K} 1=9991 \times 100 / 39970=24.99624719 \\
& \mathrm{~K} 2=9990 \times 100 / 39970=24.99374531 \\
& \mathrm{~K} 3=9996 \times 100 / 39970=25.00875657 \\
& \mathrm{~K} 4=9993 \times 100 / 39970=25.00125094
\end{aligned}
$$

Kemudian tempatkan individu antara range 1 hingga 100:

$$
\begin{aligned}
& \mathrm{K} 1=1-24.99624719 \\
& \mathrm{~K} 2=24.99624719-49.98999249 \\
& \mathrm{~K} 3=49.98999249-74.99874906 \\
& \mathrm{~K} 4=74.99874906-100
\end{aligned}
$$

Langkah pertama kali dalam pencarian jalur tercepat menggunakan metode algoritma genetika adalah pembangkitan populasi untuk menghasilkan individu terbaik. Individu kemudian diseleksi dengan roullete wheel sampai kriteria minimum fitness tercapai yang akan dilanjutkan dengan pencarian kromosom dengan nilai fitness terkecil.

\subsection{Waktu Tempuh Pengiriman Paket Data Dengan Metode Antrian}

Pengambilan data awal ping pada jaringan fiber optik Unisma terhadap 5 buah simpul inti yaitu A, B, $\mathrm{C}$, D dan E menggunakan metode antrian secara skematis dapat dilihat pada Gambar 5 dibawah ini. Garis dengan tanda panah bolak balik menunjukkan kedua simpul dapat berkomunikasi dua arah. Angka menunjukkan bobot waktu pengiriman paket data dari masing-masing arah.

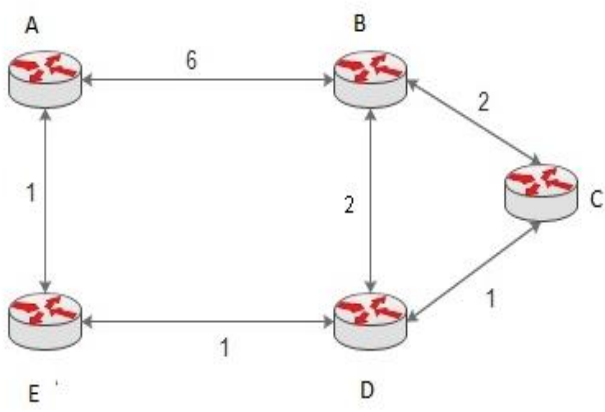

Gambar 5. Bobot Simpul Jaringan Existing Unisma dengan metode Antrian 
Deskripsi hasil pengukuran waktu tempuh pengiriman paket data antar simpul diatas menggunakan ping dalam satuan milidetik (ms) ditunjukkan pada Tabel 3.

Tabel 3. Waktu tempuh Ping antar simpul

\begin{tabular}{|c|c|c|c|c|c|}
\hline \multirow[b]{2}{*}{ Simpul Awal } & \multicolumn{3}{|c|}{ Simpul Tujuan } & \multirow[b]{2}{*}{ D } & \multirow[b]{2}{*}{$\mathrm{E}$} \\
\hline & A & B & C & & \\
\hline & Ping(ms) & Ping(ms) & Ping(ms) & Ping(ms) & Ping(ms) \\
\hline$A$ & - & 6 & - & - & 1 \\
\hline $\mathrm{B}$ & 6 & - & 2 & 2 & - \\
\hline $\mathrm{C}$ & - & 2 & - & 1 & - \\
\hline $\mathrm{D}$ & - & 2 & 1 & - & 1 \\
\hline $\mathrm{E}$ & 1 & - & - & 1 & - \\
\hline
\end{tabular}

Pengukuran FTP juga dilakukan pada simpulsimpul seperti diagram jaringan backbone sebelumnya dengan melakukan pengiriman data sebesar $164 \mathrm{MB}$. Contoh tabulasi hasil pengukuran waktu tempuh pengiriman paket data dari simpul A ke simpul lainnya dalam satuan detik (s) ditunjukkan pada Tabel 4 dibawah ini:

Tabel 4. Waktu tempuh FTP dari Simpul A

\begin{tabular}{|c|c|c|}
\hline \multirow{2}{*}{ Klien Simpul Tujuan } & \multicolumn{2}{|c|}{ Klien simpul A } \\
\cline { 2 - 3 } & Rate KBps & Waktu Tempuh (s) \\
\hline B & 6998 & 23,0 \\
\hline C & 10731 & 15,0 \\
\hline D & 10731 & 15,0 \\
\hline E & 10731 & 15,0 \\
\hline
\end{tabular}

\subsection{Optimasi Waktu Tempuh Pengiriman Paket Data Dengan Simulasi Algoritma Genetika}

Berikut ini akan dibahas tentang hasil simulasi optimasi jaringan backbone fiber optik Unisma terhadap waktu tempuh pengiriman paket data dengan parameter data ping dan FTP.

\section{Pengujian Menggunakan Data Ping}

Pengujian data ping menggunakan program visual studio yang dibangun sesuai dengan metode algoritma genetika. Hasil pengiriman paket data menggunakan ping dalam format yang ditunjukkan pada Tabel 5 dimana angka 9999 menunjukkan bahwa tidak terjadi koneksi fisik secara langsung atau hubungan pada simpul itu sendiri dan merupakan nilai maksimum kromosom.

Tabel 5. Simulasi Data ping dengan Metode Algoritma Genetika

\begin{tabular}{|c|c|c|c|c|c|}
\hline Simpul & A & B & C & D & E \\
\hline A & 9999 & 6 & 9999 & 9999 & 1 \\
\hline B & 6 & 9999 & 2 & 2 & 9999 \\
\hline C & 9999 & 2 & 9999 & 1 & 9999 \\
\hline D & 9999 & 2 & 1 & 9999 & 1 \\
\hline E & 1 & 9999 & 9999 & 1 & 9999 \\
\hline
\end{tabular}

Pengujian dengan melakukan pengukuran pada simpul-simpul yang tidak terdapat hubungan fisik secara langsung dari satu simpul awal menuju empat simpul lainnya. Data hasil pengukuran ditunjukkan oleh peneliti pada Tabel 6 untuk contoh pengiriman paket data dari satu simpul awal A menuju simpul lainnya yang menghasilkan jalur tercepat dengan waktu tempuh terkecil.

Tabel 6 Ping time Simulasi Algoritma Genetika dari Simpul A

\begin{tabular}{|c|c|c|}
\hline \multicolumn{3}{|c|}{ Simpul Awal A } \\
\hline Simpul Tujuan & Time/ms & Path \\
\hline B & 4 & A-E-D-B \\
\hline C & 3 & A-E-D-C \\
\hline D & 2 & A-E-D \\
\hline E & 1 & A-E \\
\hline
\end{tabular}

2. Gambar Optimasi Jalur Pengiriman Paket Data dengan metode Algoritma Genetika

Optimasi dilakukan dengan menghitung atau mencari bobot yang terendah dari jalur yang akan dilalui sehingga menimbulkan variasi beberapa jalur dengan nilai bobot terendah. Jalur yang telah dioptimasi dibedakan dengan garis panah 2 arah yang tebal. Jalur-jalur yang diberi garis panah tebal adalah jalur yang teroptimasi atau jalur yang dipilih oleh simulasi algoritma genetika sebagai jalur yang tercepat. Contoh hasil optimasi jalur dari simpul awal A menuju B ditunjukkan pada Gambar 6 berikut:

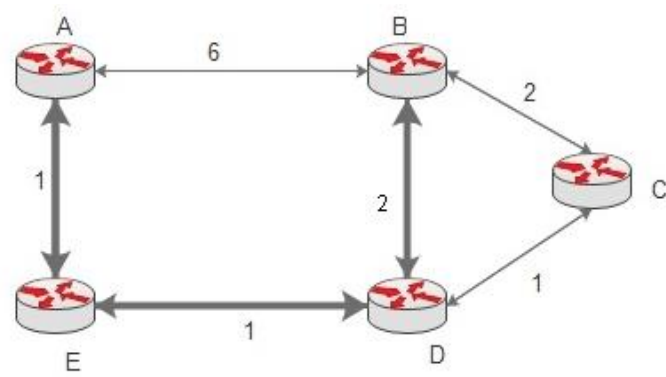

Gambar 6. Hasil Optimasi Jalur Simpul A ke B

Dari Gambar 6 diatas dapat terlihat bahwa pengiriman paket data dari simpul A ke B dimana pada jalur existing menggunakan metode antrian membutuhkan waktu $6 \mathrm{~ms}$, setelah dioptimasi dalam 
hal pemilihan jalur melalui metode algoritma genetika menghasilkan waktu tempuh $4 \mathrm{~ms}$.

\section{Pengujian menggunakan data FTP}

Data FTP pada jaringan eksisting yang menggunakan metode antrian seperti yang telah ditabulasikan pada tabel 4 diatas digunakan sebagai data pembanding terhadap data hasil simulasi dengan algoritma genetika dengan tujuan mencari jalur tercepat.

Data pengukuran FTP didapatkan dari pengolahan data ping menggunakan simulasi metode algoritma genetika, kemudian dilakukan perhitungan menggunakan rumus sebagai berikut (Clark, M. P., 2003):

$$
\text { Max throughput }=(64000 * 8) / \text { ping time }
$$

Setelah didapatkan max throughput kemudian dilakukan proses berikutnya yaitu membagi besaran file yang dijadikan acuan yaitu sebesar $164 \mathrm{MB}$ dengan max throughput untuk mendapatkan waktu tempuh pengiriman paket data menuju simpul tujuan.

Waktu tempuh $(\mathrm{t})=$ acuan besaran file/max throughput

Tabel 7 menunjukkan hasil pengujian FTP pada simpul A pada jaringan backbone fiber optik Unisma yang telah dioptimasi menggunakan algoritma genetika:

Tabel 7. Hasil Simulasi FTP Algoritma Genetika Simpul A

\begin{tabular}{|c|c|c|}
\hline \multirow{2}{*}{ Simpul Tujuan } & \multicolumn{2}{|c|}{ Simpul Awal A } \\
& Rate KBps & Waktu Tempuh (s) \\
\hline B & 12800 & 13,0 \\
\hline C & 17066 & 9,7 \\
\hline D & 25600 & 6,4 \\
\hline E & 51200 & 3,2 \\
\hline
\end{tabular}

\subsection{Perbandingan Waktu Tempuh \\ Pengiriman Paket Data Pada Jaringan Eksisting dan Setelah Optimasi Dengan Algoritma Genetika}

Perbandingan pada masing-masing simpul berupa selisih waktu tempuh pengiriman paket data menunjukkan hasil optimasi dengan algoritma genetika menghasilkan waktu yang lebih cepat. Tabel 8 menunjukkan perbandingan waktu tempuh pengiriman dari simpul A pada jaringan eksisting dengan simulasi menggunakan algoritma genetika.
Tabel 8. Perbandingan Waktu Tempuh Paket Data dari Simpul Awal A

\begin{tabular}{|c|c|c|c|}
\hline \multirow{2}{*}{ Simpul Tujuan } & \multicolumn{2}{|c|}{ Simpul Awal A } & \multirow{2}{*}{$\begin{array}{c}\text { Selisih } \\
\text { waktu }\end{array}$} \\
\cline { 2 - 3 } & Existing & Optimasi & $(\Delta$ time/s $)$ \\
\hline B & 23 & 13 & 10 \\
\hline C & 15 & 9.7 & 5.3 \\
\hline D & 15 & 6.4 & 8.6 \\
\hline E & 15 & 3.2 & 11.8 \\
\hline
\end{tabular}

Sementara tabel 9 menunjukkan perbandingan data rate pengiriman dari simpul A jaringan eksisting dengan simulasi menggunakan algoritma genetika.

Tabel 9. Perbandingan Data rate dari Simpul Awal A

\begin{tabular}{|c|c|c|c|}
\hline & \multicolumn{2}{|c|}{ Simpul Awal A } & \multirow{2}{*}{$\begin{array}{c}\text { Selisih } \\
\text { data rate }\end{array}$} \\
\cline { 2 - 3 } $\begin{array}{c}\text { Simpul } \\
\text { Tujuan }\end{array}$ & Existing & Optimasi & $(\Delta$ KBps $)$ \\
\hline B & 6998 & 12800 & 5802 \\
\hline C & 10731 & 17066 & 6335 \\
\hline D & 10731 & 25600 & 14869 \\
\hline E & 10731 & 51200 & 40469 \\
\hline
\end{tabular}

Pada gambar 7, dibuat grafik perbandingan antara jaringan existing dengan jaringan optimasi pada salah satu simpul yaitu simpul A. Hasil perhitungan waktu tempuh pengiriman paket data yang sama sebesar 164 MB dari simpul A menuju beberapa simpul tujuan, jika dibandingkan tampak bahwa hasil simulasi dengan metode algoritma genetika menunjukkan waktu tempuh yang lebih cepat dari waktu tempuh pengiriman paket data pada jaringan eksisting. Rerata penurunan waktu tempuh setelah dilakukan optimasi sebesar $8 \mathrm{~ms}$ atau mencapai hingga $53.5 \%$ jika dibandingkan dengan awal sebesar $17 \mathrm{~ms}$.

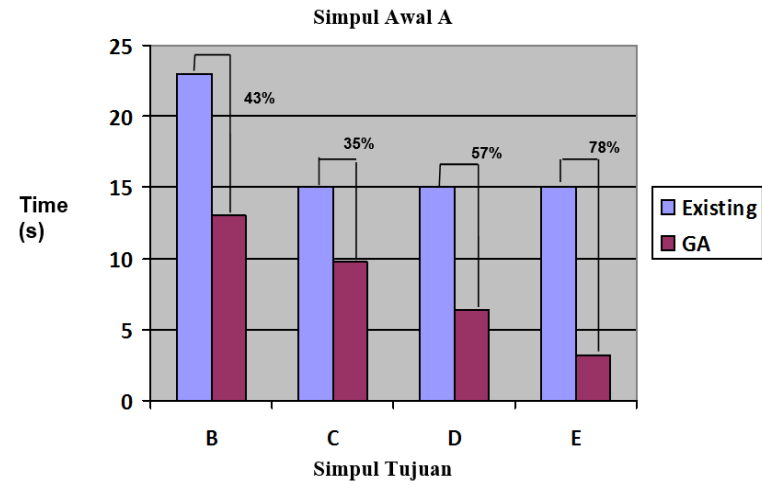

Gambar 7. Grafik Selisih Waktu Tempuh Pengiriman Paket Data dari Simpul A pada Jaringan 
Existing dibandingkan dengan Setelah Dioptimasi Menggunakan Algoritma Genetika

Sementara pada gambar 8 dibuat grafik untuk perbandingan data rate/bitrate dimana simulasi menggunakan algoritma genetika menunjukkan angka yang besar. Hal ini berpengaruh pada waktu tempuh pengiriman paket data yang dapat dilewatkan karena semakin besar data rate maka semakin cepat waktu tempuh pengiriman paket data menuju simpul tujuan. Rerata peningkatan data rate setelah dilakukan optimasi mencapai $26.666 \mathrm{KBps}$ atau $54.75 \%$ dibandingkan dengan awal sebesar 9,797 KBps.

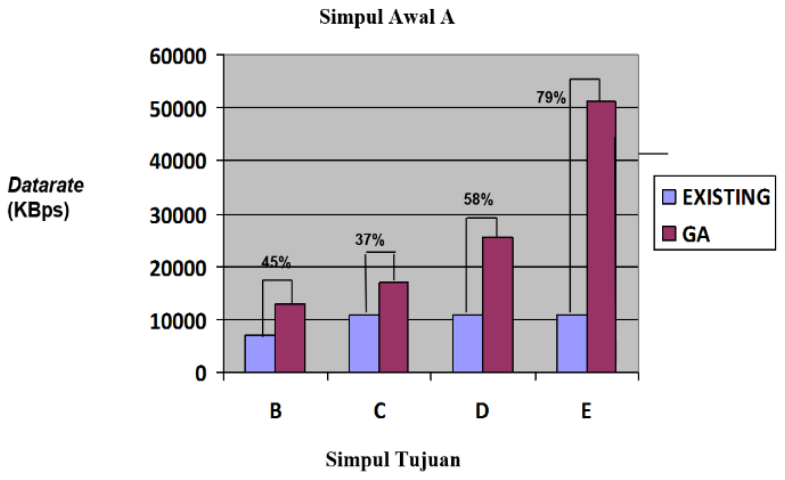

Gambar 8. Grafik Perbandingan Rate/data rate Pengiriman Paket Data dari Simpul A pada Jaringan Existing dibandingkan dengan Setelah Dioptimasi Menggunakan Algoritma Genetika

Penelitian ini membuktikan bahwa metode algoritma genetika dapat mengoptimasi kinerja jaringan backbone serat optik di Unisma yang ditunjukkan dengan hasil waktu pengiriman paket data yang lebih cepat melalui pemilihan jalur tercepat jika dibandingkan dengan jaringan existing yang menggunakan metode antrian.

Beberapa saran terkait optimasi kinerja jaringan menggunakan algoritma genetika adalah sebaiknya digunakan pada jaringan skala besar dengan traffic data yang padat, jaringan backbone sebaiknya menggunakan topologi star serta routing dinamis. Namun konsekuensinya adalah investasi dan biaya yang lebih tinggi.

\section{KESIMPULAN}

Berdasarkan hasil pengujian yang dilakukan dengan membandingkan antara metode antrian dengan algoritma genetika dapat disimpulkan bahwa proses optimasi mampu meningkatkan kecepatan pengiriman paket data pada jaringan backbone serat optik Unisma. Optimasi dengan algoritma genetika mampu menurunkan waktu tempuh dan meningkatkan data rate serta dapat digunakan untuk mencari jalur tercepat dalam pengiriman paket data.

\section{DAFTAR PUSTAKA}

ABUIZIAH, I. \& SHAKARNEH, N. 2013. A Review of Genetic Algorithm Optimization: Operations and Applications to Water Pipeline Systems. International Journal of Mathematical, Computational, Physical, Electrical and Computer Engineering Vol:7, No:12, 2013.p1782-88

ANDERSON, J. Q., BOYLES, J. L. \& RAINIE, L. 2012. The future impact of the Internet on higher education: Experts expect moreefficient collaborative environments and new grading schemes; they worry about massive online courses, the shift away from on-campus life, cited on October 2015;

http://www.pewinternet.org/topics/Futureof-the-internet.aspx, and http://www.imaginingtheinternet.org.

BISHT, N. \& SINGH, S. 2015. Analytical Study Of Different Network Topologies. International Research Journal of Engineering and Technology (IRJET), eISSN: 2395-0056 Volume: 02 Issue: 01, Mar-2015, p88-90

BONAVENTURE, O. 2011. Computer Networking:Principles, Protocols and Practice. Saylor Foundation, URL: http://www.saylor.org/courses/cs402/

CLARK, M. P. 2003. Data Networks, IP and the Internet Protocols, Design and Operation. John Wiley \& Sons, Ltd ISBN: 0-47084856-1

DUCK, M. \& READ, R. 2003. Data Communications and Computer Networks for Computer Scientists and Engineers. Second edition, Pearson Education Limited 1996, 2003

KHANDELWAL, G., PRASANNA, G. \& HOTA, C. 2011. Probabilistic Routing Using Queuing Theory For Manets. International Journal of Wireless \& Mobile Networks (IJWMN), 3, 144-157

KUMAR, D. R. \& KUMAR, M. 2010. Exploring Genetic Algorithm for Shortest Path Optimization in Data Networks. Global Journal of Computer Science and Technology, Vol. 10 Issue 11 (Ver. 1.0), p 8-12

KUMAR, R. \& KUMAR, M. 2012. Reliable and Efficient Routing Using Adaptive Genetic Algorithm in Packet Switched Networks, International Journal of Computer Science Issues, Vol. 9, Issue 1, No 3, p168-73, ISSN (Online): 1694-0814 www.IJCSI.org

Lin, X-H et al. 2002. A Genetic Algorithm Based Approach To Route Selection And Capacity Flow Assignment. Computer 
18 Jurnal Teknologi Informasi dan Ilmu Komputer (JTIIK), Vol. 3, No. 1, Maret 2016, hlm. 10-18

Communications 26 (2003) 961-974

Elsevier Inc.

SENIOR, J.M., 2008. Optical Fiber Communications, Principles Dan Practice, third edition. Pearson Education Limited 2009, ISBN: 978-0-13-032681-2 